\title{
Transcriptomic Insights into the Antifungal Effects of Magnolol on the Growth and Mycotoxin Production of Alternaria alternata
}

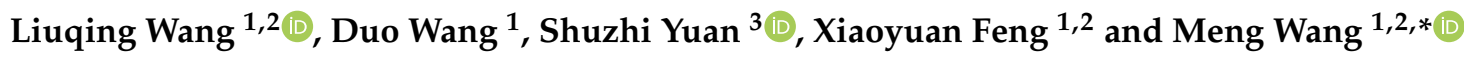 \\ 1 Beijing Research Center for Agricultural Standards and Testing, Beijing Academy of Agriculture and \\ Forestry Sciences, Haidian District, Beijing 100097, China; wanglq@brcast.org.cn (L.W.); \\ wangduo@brcast.org.cn (D.W.); fengxy@brcast.org.cn (X.F.) \\ 2 Laboratory of Quality \& Safety Risk Assessment for Agro-Products (Beijing), Ministry of Agriculture and \\ Rural Affairs, Haidian District, Beijing 100097, China \\ 3 Beijing Vegetable Research Center, Beijing Academy of Agriculture and Forestry Sciences, Haidian District, \\ Beijing 100097, China; yuanshuzhi@nercv.org \\ * Correspondence: wangm@brcast.org.cn; Tel.: +86-10-5150-3178
}

Received: 11 August 2020; Accepted: 18 October 2020; Published: 20 October 2020

\begin{abstract}
Alternaria alternata is an important phytopathogen causing fruit black rot and also producing a variety of mycotoxins, such as alternariol (AOH) and alternariol monomethyl ether (AME) as two main contaminants. This could lead to economic losses of agricultural products as well as human health risks. In this study, magnolol extracted from the traditional Chinese herb, Mangnolia officinalis, exhibited an obvious antifungal property and could completely suppress the mycelial growth at $100 \mu \mathrm{M}$. Morphological differences of A. alternata were observed to be significantly shrunk and wrinkled after the exposure to magnolol. Furthermore, $\mathrm{AOH}$ and AME were no longer produced in response to $50 \mu \mathrm{M}$ of magnolol. To uncover the antifungal and antimycotoxigenic mechanisms, the transcriptomic profiles of A. alternata-treated with or without magnolol-were evaluated. The clustered genes responsible for $\mathrm{AOH}$ and AME biosynthesis were obviously less transcribed under magnolol stress and this was further confirmed by qRT-PCR. The global regulators of carbon and nitrogen utilization, such as $\mathrm{CreA}$ and $\mathrm{NmrA}$, were significantly down-regulated and this possibly caused the reduction in mycotoxins. In addition, fatty acid $\beta$-oxidation was regarded to contribute to polyketide mycotoxin production for the supply of precursor acetyl-CoA while the expression of these related genes was inhibited. The response to magnolol led to the marked alteration of oxidative stress and the down-expression of the mitogen-activated protein kinase (MAPK) signaling pathway from the transcriptome data and the determination of peroxidase (POD), superoxide dismutase (SOD) and glutathione (GSH) assays. This above might be the very reason for the growth supression and mycotoxin production of $A$. alternata by magnolol. This study provides new insights into its potential as an important active ingredient for the control of A. alternata and its mycotoxins in fruits and their products.
\end{abstract}

Keywords: Alternaria alternata; mycotoxin; alternariol; magnolol; transcriptome

Key Contribution: Magnolol; extracted from a traditional Chinese herb; Mangnolia officinalis; exhibits brilliant suppression against Alternaria alternata and its producing mycotoxins including $\mathrm{AOH}$ and AME; especially compared to other natural phenolics. The action mode probably lies in the lower transcription of the mycotoxin biosynthetic genes and the regulatory genes of carbon and nitrogen utilization ( $\mathrm{CreA}$ and $\mathrm{NmrA}$ ), and also the disturbance of the supply of the precursor acetyl-CoA and oxidative stress. 


\section{Introduction}

The genus of Alternaria is one of the most important postharvest phytopathogens as the causal agent of fruit black rot, resulting in agricultural yield losses worldwide. A. alternata is the most common species among the genus Alternaria containing a variety of host-specific pathogenic strains [1]. In addition to economic losses and fruit quality reduction, they can produce multiple mycotoxins that are detrimental to the health of humans and animals. The Alternaria mycotoxins mainly include alternariol (AOH), alternariol monomethyl ether (AME) and tenuazonic acid (TeA) [2]. They frequently contaminate a variety of fruits, including tomatoes, apples, blueberries, grapes, and dried fruits, under suitable temperature and humidity conditions [1,3]. Of these mycotoxins, $\mathrm{AOH}$ and AME have been reported to show genotoxicity [4,5]. The genetic basis of $\mathrm{AOH}$ and $\mathrm{AME}$ biosynthesis has been elucidated and unraveled [6]. A polyketide synthase encoded by $p k s I$ is responsible and sufficient for $\mathrm{AOH}$ formation and an O-methyl transferase (omtI) transforms $\mathrm{AOH}$ to AME, the methyl ether of $\mathrm{AOH}$. A pathway specific regulatory gene, aohR, encoding a $\mathrm{Zn}$ (II)2Cys6 transcription factor activated the expression of the downstream enzymatic genes for $\mathrm{AOH}$ and $\mathrm{AME}$ production.

In consideration of pathogenic Alternaria and the mycotoxins, the prevention and control is therefore of vital point. A number of plant extracts are considered to exert brilliant antifungal activities, including some naturally occurring polyphenols. Among the polyphenols, magnolol, extracted from the traditional Chinese herb Magnolia officinalis, showed strong antifungal activities against Fusarium species [7], Candida isolates [8], Magnaporthe grisea [9], Penicillium expansum as well as A. alternata [10]. However, little is known on its inhibitory effects against Alternaria toxins, especially AOH and AME. Accordingly, the deep exploration of antifungal and antimycotoxigenic mechanisms in response to magnolol are also still unclear in A. alternata.

Therefore, the antifungal and antimycotoxigenic efficiency of magnolol was first observed to be validated in the present work. The potential mechanisms were to be investigated by comparative transcriptomic profiling between the control and magnolol-stressed A. alternata. Given that magnolol was considered safe by various food safety authorities over the past years [11], it would be a promising alternative for preservatives for the control of Alternaria pathogens and their mycotoxins.

\section{Results}

\subsection{Antifungal Effects of Magnolol on A. alternata}

The antifungal effect of magnolol against $A$. alternata ATCC 66,981 was significantly exhibited on the mycelial growth in a dose-dependent manner. After 6 days incubation, the extension of A. alternata was inhibited by $46.5 \%, 66.9 \%$ and $93.5 \%$ with $12.5,25$ and $50 \mu \mathrm{M}$ of magnolol, respectively (Figure 1 ). Similarly, the accumulation of the biomass weight was inhibited from $8.1 \%$ to $100 \%$ with the increasing magnolol (Figure 1). The extending of A. alternata was completely inhibited as the minimal inhibitory concentration (MIC) at $100 \mu \mathrm{M}$ during the whole incubation period.

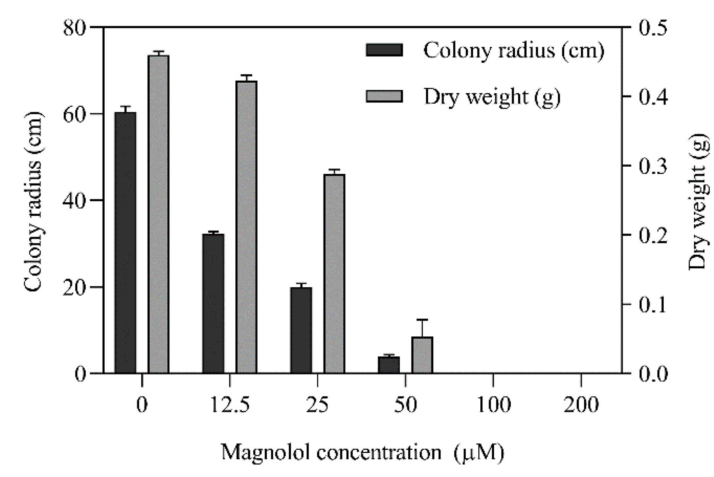

Figure 1. Inhibition of magnolol on the mycelial growth of $A$. alternata ATCC 66981. The spores were cultured in the medium plus with serial concentration of magnolol at $25^{\circ} \mathrm{C}$ for 6 days. The inhibition rates were calculated by the colony radius and dry weight. 
Ultrastructural observation by SEM indicated that there were significant morphological alterations between the control and magnolol-treated A. alternata cells. After exposure to $12.5 \mu \mathrm{M}$ of magnolol, the spores were a little shriveled (Figure 2A,B). A greater depression of morphological modifications could be observed as the magnolol concentration increased. The exposure to $25 \mu \mathrm{M}$ of magnolol caused an evidently sunken phenomenon and even a major break on the surface of the spore with no germ tubes observed (Figure 2C). The hyphae of $A$. alternata became wrinkled and abnormal after exposure to 12.5 and $25 \mu \mathrm{M}$ of magnolol (Figure 2D-F).
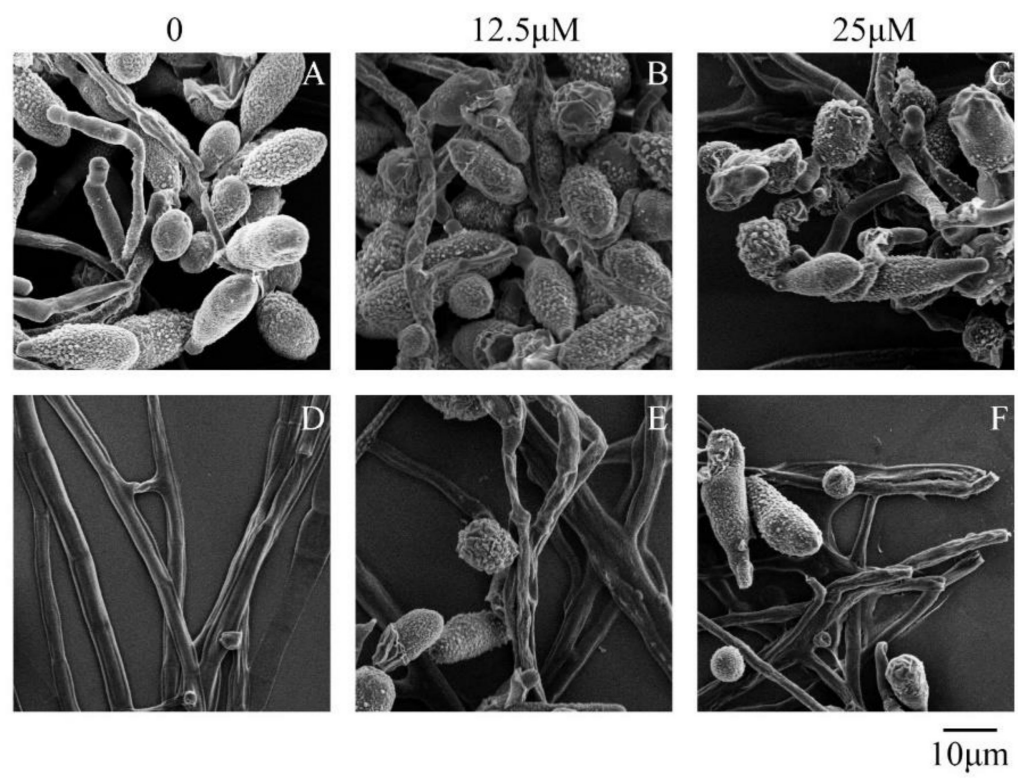

Figure 2. Scanning electron microscopy images of spores (A-C) and mycelia (D-F) of A. alternata ATCC 66,981 exposed to 0 (control), 12.5 and $25.0 \mu \mathrm{M}$ of magnolol. Bar $=10 \mu \mathrm{m}$.

\subsection{Transcriptomic Profiles of A. alternata in Response to Magnolol}

To understand the potential inhibitory mechanism of magnolol on A. alternata, a comparative transcriptome analysis of $A$. alternata was performed between 0 and $25 \mu \mathrm{M}$ of magnolol treatment. The details of the RNA-Seq data are shown in Supplementary Table S1. An average of 37.00 million and 28.63 million clean reads were separately obtained from the control and magnolol-treated group. Based on the mapped reads, the expression levels of 13,678 genes were totally quantified by the FPKM (fragments per kilobase of exon model per million mapped reads) value. The differentially expressed genes (DEGs) in accordance with the $\mid \log _{2}$ Fold Changel $\geq 1$ and false discovery rate (FDR) $<0.05$ are listed in Supplementary Table S2. Totally, 2981 genes were considered to be significantly expressed in response to magnolol at $25 \mu \mathrm{M}$, with 1471 genes up-regulated and 1510 genes down-regulated compared to untreated A. alternata samples. The distribution of these DEGs is shown in Supplementary Figure S1.

\subsection{Functional Analysis of DEGs}

The functional analysis of DEGs was used to understand the inhibitory mechanisms at the molecular level. The significant results of GO enrichment analysis were apparently different between the up-regulated and down-regulated DEGs (Figure 3A,B). The up-regulated DEGs were significantly enriched in the processes of ribosome formation and RNA and protein processing; such as rRNA processing and metabolic processes, ribosome biogenesis, non-coding RNA (ncRNA) processing and metabolic processes, and RNA processing and protein refolding, which were necessary for the survival in exposure to stress. However, the down-regulated DEGs were mostly enriched in biological processes 
and molecular functioning, such as oxidoreductase activity, antibiotic metabolic processes and catabolic processes (Figure 3B).

A

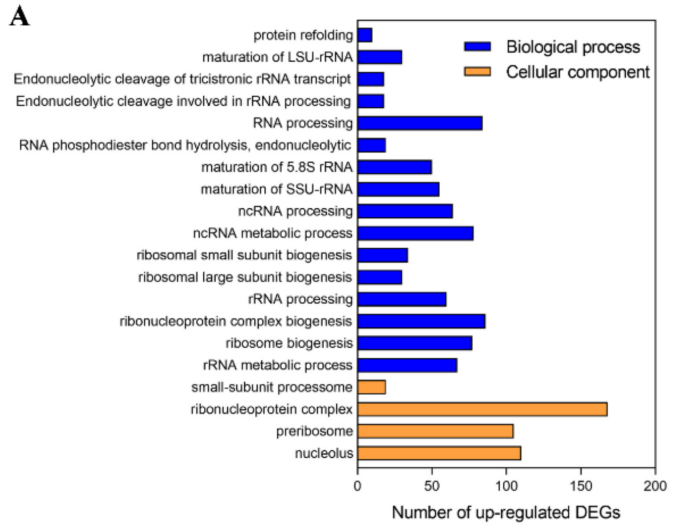

C

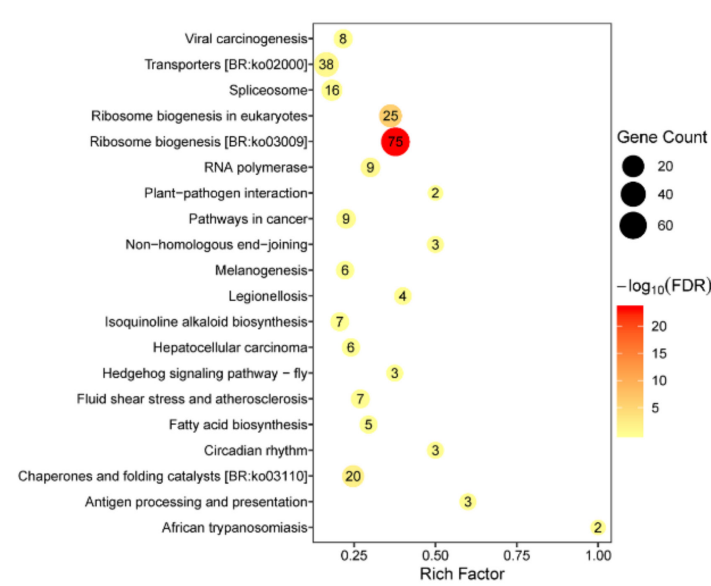

B

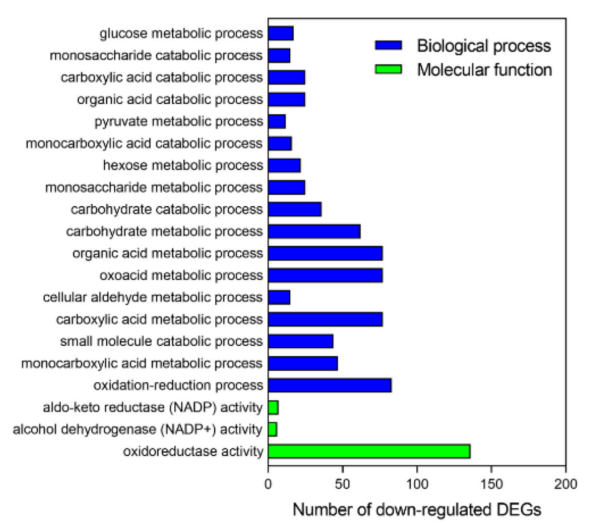

D

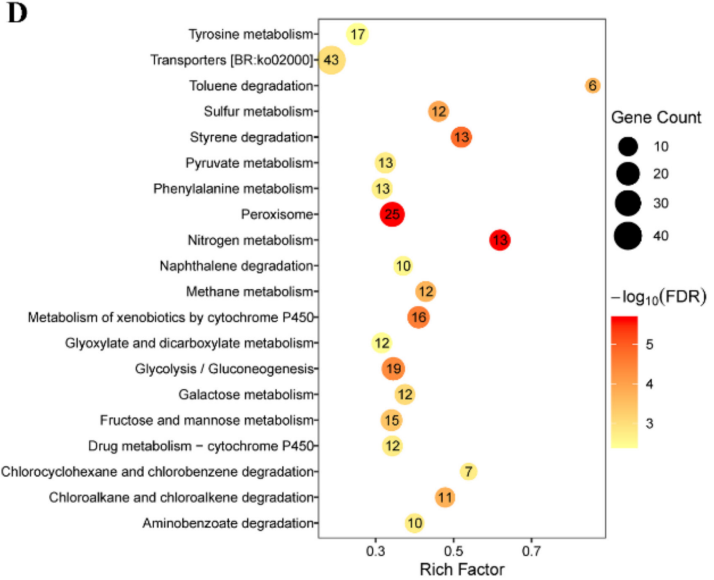

Figure 3. Gene ontology (GO) functional classification (A,B) and Kyoto Encyclopedia of Genes and Genomes (KEGG) pathway enrichment (C,D) of differentially expressed genes (DEGs). The up-regulated $(\mathbf{A}, \mathbf{C})$ and down-regulated (B,D) DEGs were separately analyzed and the top 20 results were listed at the highest enrichment level in the figure.

KEGG pathway enrichment analysis of the DEGs between magnolol and magnolol-free groups was performed to evaluate their underlying biological significance. Genes related to the ribosome biogenesis showed significantly higher expression in the magnolol treated group (Figure 3C). On the other hand, the pathways mainly belonging to the peroxisome, nitrogen metabolism, and carbohydrate and energy metabolism were suppressed significantly in the magnolol stress samples (Figure 3D).

\subsection{Genes Involved in Mycotoxin Biosynthesis}

To understand the roles of magnolol on Alternaria mycotoxins production, the expression levels of genes involved in $\mathrm{AOH}$ and $\mathrm{AME}$ biosynthesis were analyzed. Based on the transcriptome data, the transcripts of pksI and omtI, responsible for $\mathrm{AOH}$ and AME biosynthesis, were significantly down-regulated by 4.39 - and 2.28-fold when A. alternata was treated with $25 \mu \mathrm{M}$ of magnolol, respectively, whereas the $a o h R$ showed no significant difference in expression (Figure 4A). The down-regulation of pksI and omtI may directly cause a reduction in $\mathrm{AOH}$ and AME biosynthesis. In addition, co-expression of $p k s I$ with another three enzymatic genes (moxI, sdrI and doxI) was also responsible for $\mathrm{AOH}$ modification [6]. Therein, the transcripts of two genes (moxI and $s d r I$ ) were significantly down-regulated in the $25 \mu \mathrm{M}$ magnolol treated samples, while the doxI gene expression showed no significant differences (Figure 4A). The relative expression levels of three genes were 
down-regulated under magnolol stress, further confirming the results of transcriptomic analysis (Supplementary Figure S2). Meanwhile, AOH and AME production actually decreased dramatically by $86.2 \%$ and $98.2 \%$ in $25 \mu \mathrm{M}$ of magnolol treated samples by the quantitative analysis (Figure $4 \mathrm{~B}$ ).

A

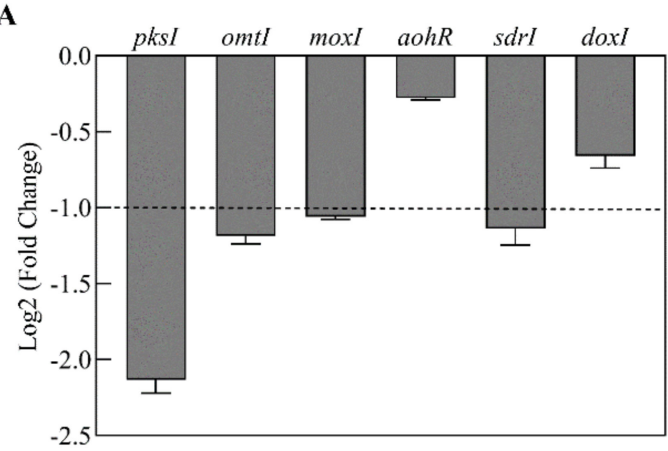

B

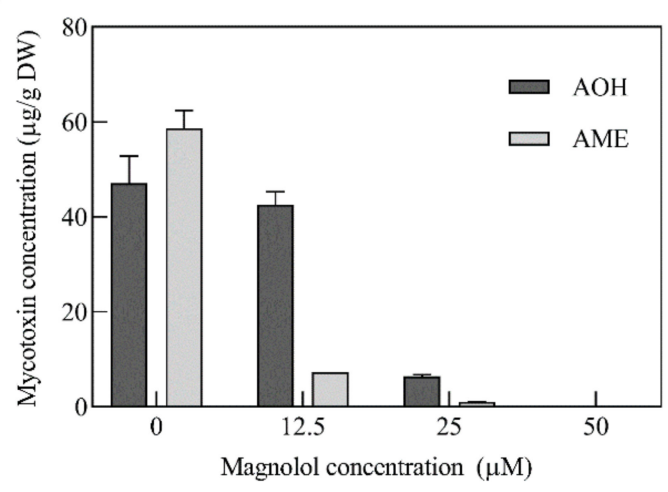

Figure 4. Effects of magnolol on the expressions of the clustered genes involved in mycotoxin biosynthesis (A), and alternariol (AOH) and alternariol monomethyl ether (AME) production (B) of A. alternata ATCC 66981. Each column represents the mean of three replicates and the results are presented as the mean \pm standard errors $(p<0.05)$.

\subsection{Genes Involved in the Primary Metabolism}

Mycotoxin production by A. alternata is influenced by nutrition factors, such as carbon and nitrogen sources $[12,13]$. It is noteworthy that the influence of the nitrogen source for $\mathrm{AOH}$ and AME production is higher than that of the carbon source [12]. KEGG metabolic pathway analysis also showed that nitrogen metabolism was suppressed to a much stronger degree after magnolol treatment. The nitrogen metabolic regulators AreA and NmrA modulate gene expression for the utilization of nitrogen sources [14]. The expression of the global nitrogen metabolic regulator AreA exhibited no significant difference compared with the magnolol-free sample. However, the transcription of $n m r A$ (CC77DRAFT_1016967) was significantly down-regulated by 2.90-fold in response to magnolol stress (Table 1). The nitrate assimilation system including nitrite reductase (NiR), nitrate reductase (NR) and a nitrate transporter NrtB was responsible for non-preferred nitrogen source utilization [15]. These genes showed lower expression from 4.31- to 5.19-fold by magnolol treatment (Table 1).

Carbon catabolite repression (CCR) plays an important role in the regulation of growth, development and secondary metabolism in mold $[16,17]$. As a principal regulator of CCR, CreA, mediates the carbon-utilizing systems. Previous studies have shown that the inactivation of $\mathrm{CreA}$ induced a marked decrease in aflatoxin biosynthesis [18,19]. In this work, the CreA (CC77DRAFT_1058240) expression level was significantly down-regulated by magnolol treatment, which suggests that CreA could also contribute to the reduction in $\mathrm{AOH}$ synthesis. In addition, $\mathrm{CreA}$ was regarded as a modulator of the cell wall integrity (CWI) pathway for the fungal resistance against antifungal agents [20], while RHO1—known as a small G protein —was considered the master regulator of CWI signaling [21]. Our data show that the presence of magnolol caused a significant down-expression of the RHO1 gene. Furthermore, some DEGs related to cell wall biogenesis markedly fluctuated by exposure to magnolol. Of the 11 DEGs, seven DEGs were down-regulated from 2.18- to 3.22-fold, and the other four DEGs were up-regulated from 2.37- to 5.82-fold (Table 1).

On the other hand, fatty acid $\beta$-oxidation contributes acetyl-CoA as a fundamental substrate for the polyketide mycotoxin production $[19,22]$. As shown in Table 1, all of the DEGs related to fatty acid $\beta$-oxidation were significantly less transcribed by 3.12 - to 8.17 -fold due to magnolol treatment. Fatty acid $\beta$-oxidation is carried out through the action of enzymes such as acyl-CoA dehydrogenase and 3-ketoacyl-CoA thiolase [23]. The expression levels of their encoding genes were down-regulated by 4.50- and 4.88-fold, respectively. 
Table 1. Effects of magnolol treatment on the differential expression of genes related to the primary metabolites in A. alternata.

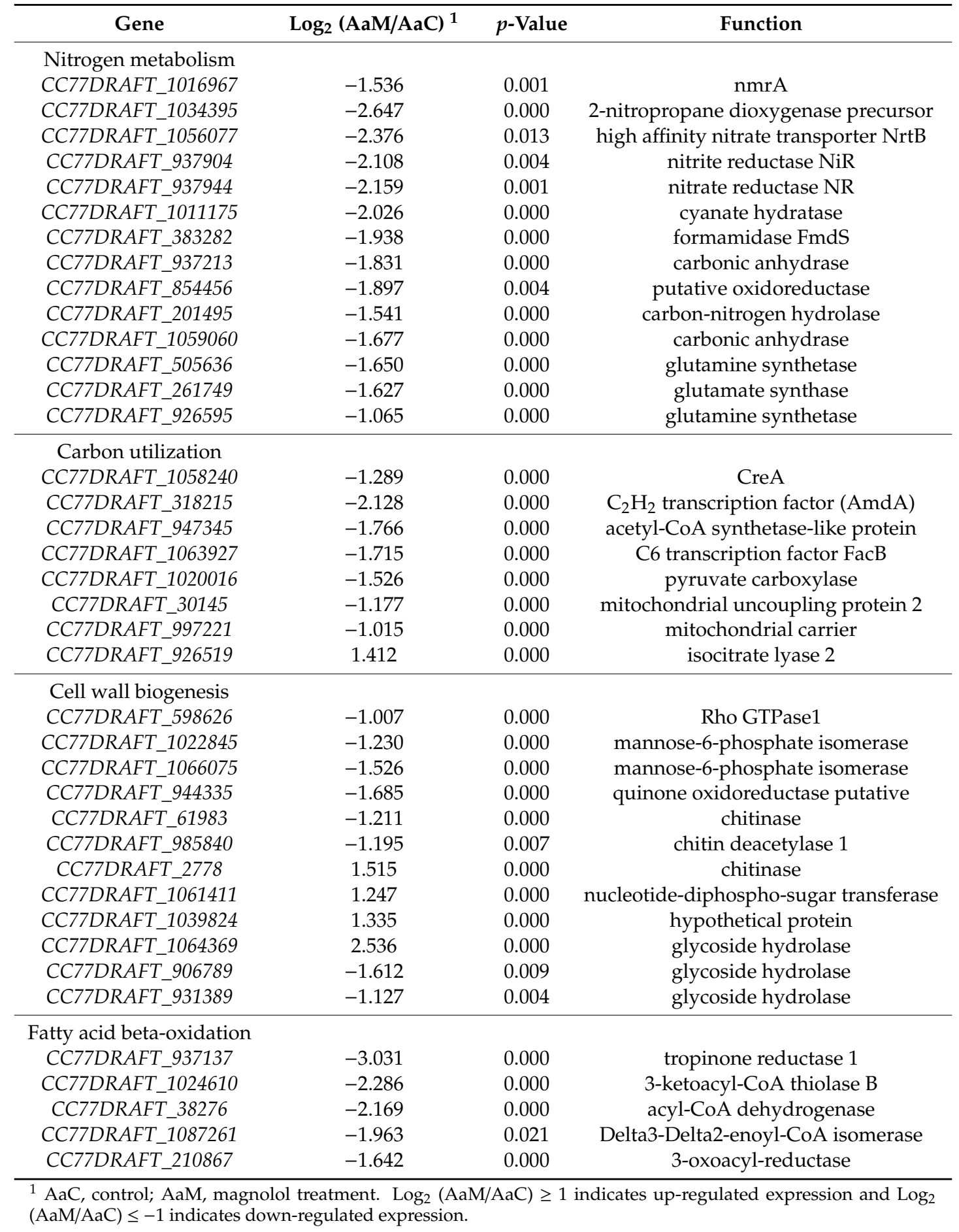

\subsection{Genes Related to Stress Response}

To overcome oxidative stress, both enzymatic and non-enzymatic systems involving peroxidase (POD), superoxide dismutase (SOD), catalase (CAT) and glutathione (GSH) have been developed for scavenging the toxic ROS in fungi. SOD catalyzes the dismutation of superoxide radicals $\left(\mathrm{O}_{2}{ }^{-}\right)$ to molecular oxygen $\left(\mathrm{O}_{2}\right)$ and hydrogen peroxide $\left(\mathrm{H}_{2} \mathrm{O}_{2}\right)$. CAT catalyzes the conversion of $\mathrm{H}_{2} \mathrm{O}_{2}$ to water and molecular oxygen. GSH is important as a cofactor for antioxidant enzymes, as a scavenger of ROS, and as a reducing agent for glutaredoxin. In this work, some DEGs involved in POD were 
up-regulated from 2.28- to 27.25-fold. Additionally, the expressions of two genes encoding SOD isozymes were also increased by 2.94- and 5.16-fold, respectively. However, the CAT encoding genes were all significantly down-regulated from 2.80- to 5.65-fold under the magnolol stress condition (Table 2). This was further confirmed by the assays of enzymatic activities, in which SOD activity in treated mycelia was enhanced by $25.6 \%$ (Figure 5A), whereas CAT activity was decreased by $41.4 \%$ compared to the control (Figure 5B).

Table 2. Effects of magnolol treatment on the significantly differential expression of the genes encoding for the antioxidant activities in A. alternata.

\begin{tabular}{|c|c|c|c|}
\hline Gene & $\log _{2}(\mathrm{AaM} / \mathrm{AaC})^{1}$ & $p$-Value & Function \\
\hline \multicolumn{4}{|l|}{ Antioxidant enzyme } \\
\hline CC77DRAFT_905830 & 1.554 & 0.000 & Superoxide dismutase (SOD) \\
\hline CC77DRAFT_911584 & 2.368 & 0.000 & SOD \\
\hline CC77DRAFT_1050117 & -1.644 & 0.000 & SOD \\
\hline CC77DRAFT_1021907 & -1.374 & 0.000 & SOD \\
\hline CC77DRAFT_1036489 & -2.497 & 0.001 & Catalase (CAT) \\
\hline CC77DRAFT_1013212 & -1.485 & 0.000 & CAT \\
\hline CC77DRAFT_296007 & 3.497 & 0.000 & Peroxidase (POD) \\
\hline CC77DRAFT_299044 & 3.421 & 0.000 & POD \\
\hline CC77DRAFT_1039208 & 1.391 & 0.000 & POD \\
\hline CC77DRAFT_960122 & 1.186 & 0.000 & POD \\
\hline CC77DRAFT_1021328 & 4.768 & 0.000 & POD \\
\hline CC77DRAFT_227615 & 1.812 & 0.000 & POD \\
\hline CC77DRAFT_1096817 & -2.209 & 0.001 & POD \\
\hline CC77DRAFT_1051184 & -1.353 & 0.015 & POD \\
\hline CC77DRAFT_1008747 & -1.162 & 0.000 & POD \\
\hline \multicolumn{4}{|l|}{ Glutathione metabolism } \\
\hline CC77DRAFT_1032529 & -3.152 & 0.000 & glutathione S-transferase II \\
\hline CC77DRAFT_687848 & -1.445 & 0.000 & glutathione S-transferase II \\
\hline CC77DRAFT_1050574 & -1.671 & 0.000 & glutamate-cysteine ligase \\
\hline CC77DRAFT_1022906 & -1.210 & 0.000 & glutamate-cysteine ligase regulatory subunit \\
\hline CC77DRAFT_77574 & -2.371 & 0.000 & thioredoxin-like protein \\
\hline CC77DRAFT_1056344 & 1.282 & 0.001 & glutathione S-transferase \\
\hline CC77DRAFT_356794 & 1.067 & 0.001 & glutathione S-transferase \\
\hline \multicolumn{4}{|l|}{ Siderophore biosynthesis } \\
\hline CC77DRAFT_935643 & 1.464 & 0.000 & tyrosinase \\
\hline CC77DRAFT_1061171 & 2.376 & 0.000 & Non-ribosomal peptide synthase, NPS6 \\
\hline CC77DRAFT_1031046 & 2.732 & 0.000 & $\mathrm{ABC}$ transporter \\
\hline CC77DRAFT_1020276 & 4.384 & 0.000 & L-ornithine 5-monooxygenase \\
\hline CC77DRAFT_69570 & 2.126 & 0.000 & aerobactin siderophore biosynthesis protein iucB \\
\hline CC77DRAFT_69691 & 4.699 & 0.000 & short-chain-fatty-acid-CoA ligase, sidI \\
\hline CC77DRAFT_71629 & 4.417 & 0.000 & siderophore iron transporter, mirB \\
\hline CC77DRAFT_69581 & -2.210 & 0.000 & MFS transporter \\
\hline \multicolumn{4}{|l|}{ Sulfur metabolism } \\
\hline CC77DRAFT_1015694 & -3.069 & 0.000 & thiosulfate sulfurtransferas-like protein \\
\hline CC77DRAFT_1020633 & -1.427 & 0.000 & sulfite reductase hemoprotein \\
\hline CC77DRAFT_1022955 & -3.093 & 0.000 & o-acetylhomoserine ami \\
\hline CC77DRAFT_1067622 & -2.515 & 0.000 & molybdopterin binding oxidoreductase \\
\hline CC77DRAFT_1099663 & -1.502 & 0.000 & sulfide: quinone oxidoreductase \\
\hline CC77DRAFT_675919 & -1.094 & 0.000 & carbohydrate phosphatase \\
\hline CC77DRAFT_786633 & -1.703 & 0.000 & adenylyl-sulfate kinase \\
\hline CC77DRAFT_925110 & -2.268 & 0.000 & phosphoadenosine phosphosulfate reductase \\
\hline CC77DRAFT_951586 & -1.374 & 0.000 & ATP-sulfurylase \\
\hline CC77DRAFT_971236 & -5.474 & 0.000 & methanesulfonate monooxygenase \\
\hline CC77DRAFT_192219 & -1.215 & 0.000 & alpha/beta-hydrolase \\
\hline CC77DRAFT_240786 & -1.437 & 0.000 & homoserine acetyltransferase family protein \\
\hline
\end{tabular}

${ }^{1} \mathrm{AaC}$, control; $\mathrm{AaM}$, magnolol treatment. $\log _{2}(\mathrm{AaM} / \mathrm{AaC}) \geq 1$ indicates up-regulated expression and $\log _{2}$ $(\mathrm{AaM} / \mathrm{AaC}) \leq-1$ indicates down-regulated expression. 

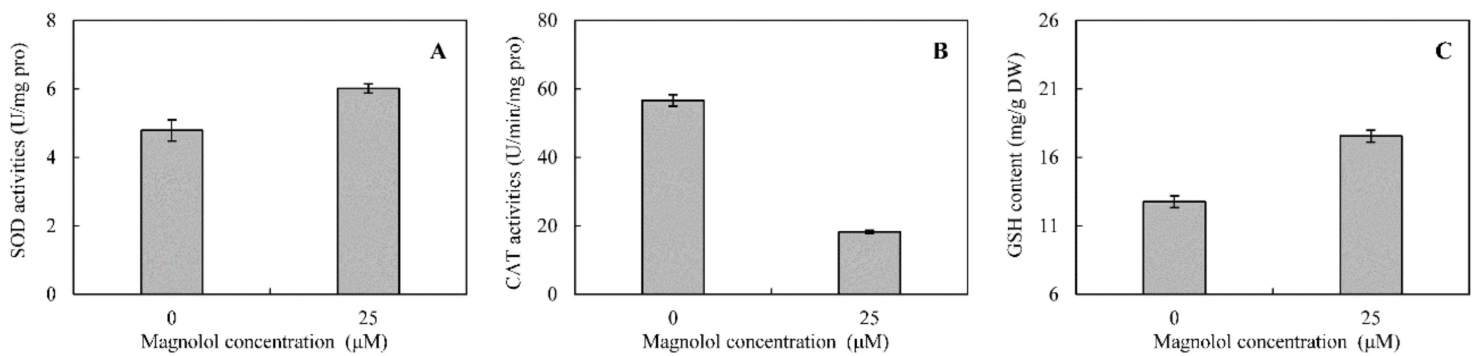

Figure 5. Effects of magnolol on the superoxide dismutase (SOD) and catalase (CAT) activities (A,B), and glutathione (GSH) content (C) of A. alternata ATCC 66981. SOD catalyzes the dismutation of superoxide radicals $\left(\mathrm{O}_{2}{ }^{-}\right)$to molecular oxygen $\left(\mathrm{O}_{2}\right)$ and hydrogen peroxide $\left(\mathrm{H}_{2} \mathrm{O}_{2}\right)$. CAT catalyzes the conversion of $\mathrm{H}_{2} \mathrm{O}_{2}$ to water and molecular oxygen. GSH is important as a cofactor for antioxidant enzymes, as a scavenger of ROS, and as a reducing agent for glutaredoxin. Each column represents the mean of three replicates. Results are presented as the mean \pm standard error $(p<0.05)$.

Glutathione is the principal non-enzymatic compound protecting cells from oxidative stress [24]. As shown in Table 2, the DEGs related to GSH metabolism were down-regulated from KEGG analysis. Some glutathione S-transferases, which could catalyze the conjugation between GSH and many xenobiotic compounds for the purpose of detoxification, were less expressed by 2.72- and 8.89-fold. Correspondingly, the GSH contents were reduced by $20.7 \%$ in the magnolol treatment, compared to the control (Figure 5C). Moreover, sulfur-containing defense compounds involved in sulfur metabolism, including GSH and various sulfur-rich proteins, are crucial for fungal resistance against abiotic stress $[25,26]$. Our results showed that the expressions of 12 DEGs related to sulfur metabolism were totally repressed by magnolol.

In A. alternata, several oxidative stress-related proteins, mainly including the redox-responsive Yap1, the high osmolarity glycerol 1 (Hog1) mitogen-activated protein (MAP) kinase, the Skn7 response regulator and the non-ribosomal peptide synthetase (NPS6), have demonstrated to be involved in ROS modulation [27]. The transcriptomic profile showed that the expression of Hog1 (CC77DRAFT_164856) was significantly down regulated by magnolol treatment. Conversely, an increase of 5.19-fold in the expression of NPS6 (CC77DRAFT_1061171) was observed. NSP6, catalyzing the biosynthesis of siderophores, may assist the fungus to chelate iron and play a critical role for antioxidant activities and ROS detoxification [28]. Of the eight DEGs related to siderophore biosynthesis, except the major facility superfamily (MFS) transporter encoding gene, seven DEGs were overexpressed from 2.76- to 25.97-fold in response to the magnolol stress (Table 2). It is worth noting that the transcription factors Yap1 and Skn7 were demonstrated as having no significant change compared to the control.

\section{Discussion}

Magnolol is known as one of major bioactive compounds from Magnolia officinalis and has been reported to have biological functions such as anti-inflammatory, antifungal, anti-cancer and antioxidant activities $[9,10]$. Previous studies have showed that even at quite low concentrations magnolol exhibited high efficacy and strong potency against a broad spectrum of toxigenic fungi, including Alternaria spp. $[9,10]$ and Fusarium spp. $[7,9,29]$. The mycelial extending and biomass weight of $A$. alternata in our work could be strongly inhibited by up to $93.5 \%$ and $88.3 \%$ with the treatment of magnolol only at $25 \mu \mathrm{M}$. Moreover, the MIC value of magnolol on A. alternata was much lower than that of other natural phenolics including $p$-coumaric, ferulic and caffeic acids [30,31]. Therefore, magnolol could be a potential alternative for controlling Alternaria decay. Chemical fungicides could possibly lead to fungal resistance and environmental problems. For this reason, many countries have established legislation to restrict the overuse of the chemical agents. The plant-derived magnolol is promising because of its non-phytotoxic, readily biodegradable, and environmentally safe properties. The major limitation of magnolol lies in its poor water solubility. Magnolol could be developed 
to be emulsified for antifungal efficiency. Additionally, the nanoparticle formulation of magnolol is recognized to be worthy to be explored for the improvement of its water solubility, such as the therapeutic formulation of magnolol nanoparticles [32].

Besides the pathogenic Alternaria fruits and their products, it is necessary to evaluate the magnolol effects on mycotoxins because little has been revealed. Of these mycotoxins, $\mathrm{AOH}$ and AME were demonstrated to be two of the most frequently contaminated mycotoxins [26,33]. To our knowledge, magnolol was first reported to have intense inhibitory effects on AOH and AME production in the present work, and $50 \mu \mathrm{M}$ of magnolol could completely suppress mycotoxin biosynthesis. Similarly, type B trichothecene production by F. culmorum was significantly inhibited by magnolol treatment probably due to the presence of the free phenolic hydroxyl group on magnolol [29]. Actually, our previous studies showed that phenolics could be potent inhibitors against mycotoxin production in A. alternata [31]. Moreover, phenolics showed strong inhibition of aflatoxin and ochratoxin A biosynthesis by Aspergillus [19,34] and trichothecenes production by Fusarium [29,35]. Based on these results, the antifungal and antimycotoxigenic mechanism of magnolol on $A$. alternata growth and mycotoxin production was further investigated by transcriptomic analysis.

In $A$. alternata, the biosynthesis of $\mathrm{AOH}$ and its derivatives is managed by a polyketide gene cluster in which $a o h R$ serves as a positive transcriptional factor for mycotoxin production [6]. Our RNA-Seq data have shown that the clustered enzyme genes involved in AOH and AME biosynthesis were less transcribed, but for the expression of the regulatory gene $a o h R$ there was no significant decrease after the magnolol treatment. PksI was proven to be sufficient for $\mathrm{AOH}$ formation in A. alternata, while omtI was responsible for AME formation from the methyl ether of $\mathrm{AOH}$ [6]. Our previous study also found that the expression of pksI and omtI was strongly down-regulated by the essential oil citral, although the regulator $a o h R$ showed no significant change [26]. A similar result was reported by Zhao and his colleagues [19]. They found that most structural genes in the aflatoxin biosynthetic gene cluster were down-regulated while regulators aflR and aflS were not significantly affected by gallic acid [19]. Taken together, these finding indicated that magnolol inhibited mycotoxin production by lowering the expression of $p k s I$ and omtI.

Acetyl-CoA is the precursor for AOH formation [36], and it is mainly produced from fatty acid $\beta$-oxidation and pyruvate decarboxylation [19]. It was reported that gallic acid and cinnamaldehyde inhibited aflatoxin formation via the lower expression of fatty acid $\beta$-oxidation genes [19,37]. Our results also showed that all of the DEGs involved in fatty acid $\beta$-oxidation were highly repressed after exposure to magnolol. The last step of the $\beta$-oxidation cycle requires A 3-ketoacyl-CoA thiolase (KAT) enzyme which is essential for the last step of the $\beta$-oxidation cycle catalyzing fatty ketoacyl-CoA to produce one acetyl-CoA molecule [38]. It is worth noting that the expression of KAT was significantly down-regulated by 4.88 -fold under magnolol stress. Therefore, the suppression of the DEGs responsible for the fatty acid $\beta$-oxidation pathway by magnolol would likely inhibit mycotoxin biosynthesis due to lack of precursors.

The growth and mycotoxin production in fungi is also influenced by the available carbon and nitrogen sources and the corresponding regulators [20,39,40]. The transcription factors CreA, AreA and NmrA play important roles in modulating the expression of genes for utilizing these nutrient sources $[14,16,41]$. Furthermore, CreA is essential for controlling secondary metabolism, either directly by interacting with the consensus sequences on the promoter region of mycotoxin biosynthetic genes or through transcriptional cascades and disruption of nutrient utilization [19]. Indeed, the deletion of CreA in A. flavus caused the significant repression of gene expression in aflatoxin biosynthesis and almost completely inhibited mycotoxin production $[19,20]$. Therefore, the downregulation of CreA could possibly lead to the decrease in AOH and AME production in A. alternata under the magnolol stress. In the nitrogen metabolic regulation, although there was no obvious significant difference in AreA expression, NmrA demonstrated lower levels of transcription in A. alternata with magnolol treatment. NmrA appears to affect gene expression through physical interaction with AreA [42], and also be involved in the mycotoxin biosynthesis and virulence of pathogens [18,40]. The NmrA 
deletion partially restricted the production of aflatoxin [40] and deoxynivalenol [43] in some minimal media with one amino acid as the sole nitrogen resource. These results suggest that the downregulation of CreA and NmrA under the magnolol stress may contribute to the significant reduction in $\mathrm{AOH}$ and AME production. It is noteworthy that CreA may be involved in nitrogen catabolite repression [41], while NmrA was considered to regulate carbon metabolism [44].

In addition to the nutritive factors, oxidative stress induced by environmental stimuli plays a crucial role in mycotoxin biosynthesis in fungi [24,45]. Oxidative stress was reported to stimulate the production of mycotoxins, including deoxynivalenol by F. graminearum [46], ochratoxin A by A. ochraceus [45] and aflatoxin by A. flavus [37] and A. parasiticus [47]. Likewise, fungi can cope with ROS toxicity by activating enzymatic and nonenzymatic defense systems, since excessive accumulation of ROS can lead to cellular dysfunction and even be lethal to cells. Several studies have reported that antioxidants could inhibit mycotoxin production by positive regulation of the antioxidant system and reducing the ROS in fungi $[19,48]$. However, a variety of inhibitors may act on the different types of antioxidant system. For example, gallic acid inhibited aflatoxin biosynthesis and stayed oxidative stress homeostasis in A. flavus by activating the nonenzymatic antioxidant system [19], while piperine depressed aflatoxin production accompanied with enhancement of CAT activity [48]. In this work, we found that exposure to magnolol led to the up-regulation of antioxidant enzymes in A. alternata, such as SOD and POD, while the CAT activity showed a sharp decrease. Similar trends were also observed by previous studies on the inhibitory effects of essential oils on the biosynthesis of patulin [49] and aflatoxin $B_{1}$ [50]. They stated that essential oils suppressed mycotoxin production through enhancing SOD activity. In addition, siderophore-mediated iron uptake plays an important role in resistance to the toxic ROS which could be detoxified by SOD and CAT in A. alternata [28]. Our results show that almost all genes involved in siderophore biosynthesis were highly up-regulated after magnolol treatment. Meanwhile, iron present in excess could detoxify ROS via a non-enzymic system [28]. Taken together, it seems that the enhancement of SOD and POD activities and siderophore biosynthesis in $A$. alternata play important roles in the elimination of ROS and the inhibition of mycotoxin production by magnolol stress.

Oxidative stress leads to the response of gene transcription regulated by specific transcription factors and protein phosphorylation signaling pathways in fungi [24]. However, transcription factors like Yap and SKN7, which are responsible for regulating the oxidative response and ROS detoxification in A. alternata [27], did not show any significant difference under the magnolol condition. The other type is reported to be the modulation of the mitogen-activated protein kinase (MAPK) pathways [24]. Two MAPK pathways, the HOG and CWI pathways, are so vital for the adaptation of the cell to stress [51]. Our results showed that Hog1, the key MAPK of the HOG pathway, was significantly downregulated by magnolol. In fact, the Hog deletion mutant of A. alternata was almost unable to produce $\mathrm{AOH}$, indicating that $\mathrm{AOH}$ biosynthesis required a phosphorylated HOG [52]. Additionally, Hog1 also modulates the production of several mycotoxins, such as fumonisin $B_{1}$ [53] and ochratoxin A [54]. The CWI pathway is responsible for the maintenance of the cell wall, which is a common target for antifungal compounds [55,56]. This pathway is regulated by the RHO family of GTPases, of which RHO1 is considered the center regulator [21]. Previous studies have demonstrated that an increase in the transcription levels of RHO1 corresponded to a higher accumulation of AOH and AME, suggesting that the mycotoxin biosynthesis might be related to the CWI pathway [21,55]. Indeed, a significant inhibition of the RHO1 expression exposure to magnolol treatment was observed, indicating that the fungus was unable to activate the CWI pathway to overcome the stress. Meanwhile, the results from SEM microscopy also showed that magnolol destroyed cell wall integrity and permeability, which was consistent with the previous SEM observations on A. alternata treated with ethyl $p$-coumarate [30]. Taking the above into account, magnolol displayed strong antifungal and antimycotoxigenic activities against $A$. alternata by repressing the HOG and CWI signaling pathways and affecting cell wall integrity. 


\section{Conclusions}

Magnolol exerts strong inhibitory effects on the growth and mycotoxin biosynthesis of A. alternata in this study, and the results provide a new insight into the global transcriptional alterations of A. alternata in response to magnolol stress. Based on the transcriptional profile, our results demonstrate in Figure 6 that: (1) magnolol inhibits the $\mathrm{AOH}$ and AME biosynthesis by down-expression of the polyketide clustered genes, including $p k s I$ and $o m t I$; (2) the suppression of fatty acid $\beta$-oxidation after magnolol treatment leads to the marked reduction in mycotoxin precursor acetyl-CoA; (3) the down-regulation of nutritive repression regulators $\mathrm{CreA}$ and $\mathrm{NmrA}$ in response to magnolol may contribute to the significant decline in $\mathrm{AOH}$ and AME production; (4) magnolol enhances the expression of genes encoding antioxidant defense including SOD, POD and siderophore biosynthesis, together with the inhibition of the HOG and CWI signaling pathways, suggesting that magnolol inhibits AOH and AME production of $A$. alternata via the perturbation of the oxidative stress balance. In summary, magnolol could be a potential alternative to the traditional fungicides for controlling Alternaria decay and reducing mycotoxin contamination.

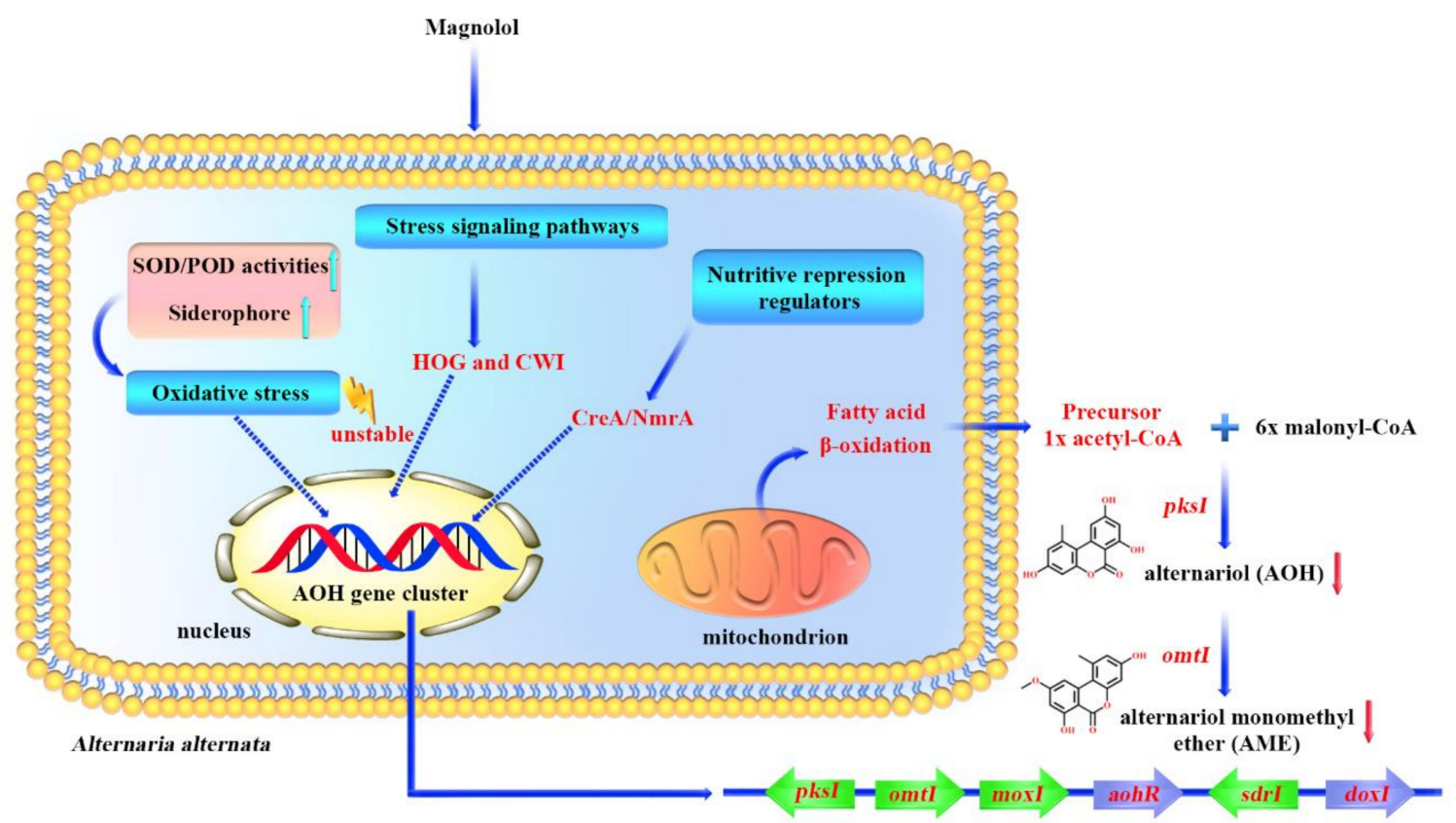

Figure 6. The schematic diagram demonstrating the inhibitory effects of magnolol against $A$. alternata and its mycotoxins. HOG: high osmolarity glycerol signaling pathway; CWI: cell wall integrity signaling pathway.

\section{Materials and Methods}

\subsection{Strain and Culture Condition}

A. alternata ATCC 66,981 was grown on potato dextrose agar (PDA; Becton Dickinson, Franklin Lakes, NJ, USA) at $25{ }^{\circ} \mathrm{C}$ for 7 days in order for the preparation of spore suspensions as the previous study [57]. The spore concentration was finally adjusted to $1 \times 10^{5}$ spores $/ \mathrm{mL}$ using a hemocytometer for the following assays.

\subsection{Antifungal Effects of Magnolol on A. alternata}

Magnolol, purchased from Sigma-Aldrich (St. Louis, MO, USA), was dissolved with 50\% aqueous ethanol $(v / v)$ to prepare for the stock solution. It was mixed with the medium to obtain the different concentrations $(0,12.5,25,50,100$ and $200 \mu \mathrm{M})$. Antifungal trials of magnolol were performed as our previous work with slight modifications [31]. A total of $5 \mu \mathrm{L}$ aliquot of spore suspension was inoculated 
on PDA medium with serial concentrations of magnolol and cultured at $25^{\circ} \mathrm{C}$ for 6 days for diameter determination. In addition, liquid culture was carried out using potato dextrose broth (PDB; Becton Dickinson, Franklin Lakes, NJ, USA) at the final concentration of $10^{2}$ spores $/ \mathrm{mL}$ with shake flask culture in an incubator at $25^{\circ} \mathrm{C}, 180 \mathrm{r} / \mathrm{min}$. The minimum inhibitory concentration (MIC) was recognized as the lowest concentration of magnolol without visible fungal extending. After incubation for $6 \mathrm{~d}$, the culture was filtered with Whatman filter paper. The supernatant was used for the determination of $\mathrm{AOH}$ and AME contents, while the mycelium was freeze-dried for the biomass analysis or quickly frozen with liquid nitrogen for the following RNA extraction. Each test was performed in triplicate. The inhibition ratio of the mycelial growth and biomass weight was separately calculated.

\subsection{Scanning Electron Microscopy (SEM) Analysis}

The mycelia of A. alternata were collected and washed three times using phosphate buffered saline (PBS; pH 7.4) after $72 \mathrm{~h}$ incubation. The mycelia were mixed with PDB medium with $0,12.5$ or $25 \mu \mathrm{M}$ of magnolol (mycelial weight: the volume of the medium $=1: 10$ ).

For the analysis of spore morphological changes, spore suspension was mixed with the antifungal agent to get the magnolol final concentrations of $0,12.5$ and $25 \mu \mathrm{M}$. After incubation at $25^{\circ} \mathrm{C}, 180 \mathrm{r} / \mathrm{min}$ for $12 \mathrm{~h}$, both mycelia and spores were centrifuged for $5 \mathrm{~min}$ at $10,000 \times g$, resuspended with PBS to remove the residue of medium and magnolol. The samples were then followed by serial pretreatments for the microscope observation based on Wang et al. [26]. Finally, the morphological alteration was compared using a scanning electron microscope (S-3400N, Hitachi, Tokyo, Japan).

\subsection{AOH and AME Analysis}

The extraction of $\mathrm{AOH}$ and AME was carried out following by the method of Meena et al. [58] with minor modification. The culture was added with equal volume of acetonitrile containing $0.1 \%(v / v)$ formic acid, vortexed for $3 \mathrm{~min}$ and then kept at $4{ }^{\circ} \mathrm{C}$ for $24 \mathrm{~h}$. After the centrifugation, the supernatant was processed and $\mathrm{AOH}$ and $\mathrm{AME}$ accumulation was quantified under the direction of Wang et al. [26].

\subsection{RNA Extraction, cDNA Library Construction, and RNA-Seq Analysis}

RNA was extracted from 6 days cultured mycelia from A. alternata ATCC 66981 grown in PDB medium with or without $25 \mu \mathrm{M}$ of magnolol using TRIzol reagent (Invitrogen, Carlsbad, CA, USA) following the manufacturer's instructions. Each group has three biological replications. Extracted RNA was evaluated with the agarose gel electrophoresis and the Qubit RNA Assay Kit (Invitrogen, Carlsbad, CA, USA). The cDNA libraries construction and RNA-seq was performed at Beijing Geek Gene Technology Co., Ltd. (Beijing, China).

The reads adapters, low quality reads, and reads with more than $5 \% \mathrm{~N}$ were to be trimmed from the raw reads. The remaining reads were conducted to be bioinformatically analyzed based on the genome annotation of A. alternata (genome assembly: GCF_001642055.1) [27]. The genes of significantly differential expression between these compared samples were analyzed. Finally, gene ontology (GO) functional annotation and Kyoto Encyclopedia of Genes and Genomes (KEGG) pathway enrichment analysis were carried out to understand the functions of the differentially expressed genes (DEGs). To further confirm the reliability of the results from the gene expression analysis by RNA-Seq, quantitative reverse transcription polymerase chain reaction (qRT-PCR) was conducted for the clustered genes that were involved in AOH and AME biosynthesis by the reference of Wang et al. [26].

\subsection{Antioxidant Enzymatic Activities and Glutathione Measurement}

To evaluate the impact of magnolol on the antioxidant system activities in A. alternata, the analyses of superoxide dismutase (SOD), catalase (CAT) and glutathione (GSH) were performed following the same culture conditions of RNA extraction. The enzymatic activities of SOD and CAT, and the content of GSH were determined by the respective detection kits (Solarbio, Beijing, China) following the instructions. 


\subsection{Statistical Analysis}

Statistical analyses of all the results were completed by Microsoft Excel 2016. The significant difference of each treatment was compared by one-way analysis of variance (ANOVA) with the least significant differences' test (LSD test) at $p<0.05$ using IBM SPSS Statistics 21.0 (SPSS Inc., Chicago, IL, USA).

Supplementary Materials: The following are available online at http:/www.mdpi.com/2072-6651/12/10/665/s1. Figure S1: Volcano plot of these differentially expressed genes (DEGs) of A. alternata treated with $25 \mu \mathrm{M}$ of magnolol vs. control, Figure S2: Comparative analysis of gene expression of A. alternata in 0, 12.5, $25 \mu \mathrm{M}$ of magnolol by quantitative reverse transcription PCR (qRT-PCR), Table S1: Summary of the RNA-Seq data in the control (AaC) and $25.0 \mu \mathrm{M}$ magnolol treated (AaM) groups of A. alternata ATCC 66981, Table S2: Differentially expressed genes (DEGs) between the control and magnolol stressed samples of A. alternata.

Author Contributions: Conceptualization, L.W. and M.W.; methodology, L.W. and D.W.; validation, L.W. and M.W.; investigation, L.W. and D.W.; resources, L.W. and D.W.; writing-original draft preparation, L.W. and M.W.; writing - review and editing, S.Y. and X.F.; funding acquisition, L.W. and M.W. All authors have read and agreed to the published version of the manuscript.

Funding: This research was funded by the National Natural Science Foundation of China (grant no. 31701709; 31801648), and the Innovation and Capacity-building Projects by Beijing Academy of Agriculture and Forestry Sciences (grant no. KJCX20180408).

Conflicts of Interest: The authors declare no conflict of interest.

\section{References}

1. Logrieco, A.; Moretti, A.; Solfrizzo, M. Alternaria toxins and plant diseases: An overview of origin, occurrence and risks. World Mycotoxin J. 2009, 2, 129-140. [CrossRef]

2. Sanzani, S.M.; Reverberi, M.; Geisen, R. Mycotoxins in harvested fruits and vegetables: Insights in producing fungi, biological role, conducive conditions, and tools to manage postharvest contamination. Postharvest Biol. Technol. 2016, 122, 95-105. [CrossRef]

3. Wei, D.; Wang, Y.; Jiang, D.; Feng, X.; Li, J.; Wang, M. Survey of Alternaria toxins and other mycotoxins in dried fruits in China. Toxins (Basel) 2017, 9, 200. [CrossRef] [PubMed]

4. Solfrizzo, M. Recent advances on Alternaria mycotoxins. Curr. Opin. Food Sci. 2017, 17, 57-61. [CrossRef]

5. Solhaug, A.; Eriksen, G.S.; Holme, J.A. Mechanisms of action and toxicity of the mycotoxin alternariol: A review. Basic Clin. Pharmacol. Toxicol. 2016, 119, 533-539. [CrossRef]

6. Wenderoth, M.; Garganese, F.; Schmidt-Heydt, M.; Soukup, S.T.; Ippolito, A.; Sanzani, S.M.; Fischer, R. Alternariol as virulence and colonization factor of Alternaria alternata during plant infection. Mol. Microbiol. 2019, 112, 131-146. [CrossRef]

7. Oufensou, S.; Scherm, B.; Pani, G.; Balmas, V.; Fabbri, D.; Dettori, M.A.; Carta, P.; Malbrán, I.; Migheli, Q.; Delogu, G. Honokiol, magnolol and its monoacetyl derivative show strong anti-fungal effect on Fusarium isolates of clinical relevance. PLoS ONE 2019, 14, e221249. [CrossRef]

8. Behbehani, J.; Shreaz, S.; Irshad, M.; Karched, M. The natural compound magnolol affects growth, biofilm formation, and ultrastructure of oral Candida isolates. Microb. Pathog. 2017, 113, 209-217. [CrossRef]

9. Choi, N.H.; Choi, G.J.; Min, B.S.; Jang, K.S.; Choi, Y.H.; Kang, M.S.; Park, M.S.; Choi, J.E.; Bae, B.K.; Kim, J.C. Effects of neolignans from the stem bark of Magnolia obovata on plant pathogenic fungi. J. Appl. Microbiol. 2009, 106, 2057-2063. [CrossRef]

10. Chen, Y.-H.; Lu, M.-H.; Guo, D.-S.; Zhai, Y.-Y.; Miao, D.; Yue, J.; Yuan, C.; Zhao, M.; An, D. Antifungal Effect of magnolol and honokiol from Magnolia officinalis on Alternaria alternata causing tobacco brown spot. Molecules 2019, 24, 2140. [CrossRef]

11. Sarrica, A.; Kirika, N.; Romeo, M.; Salmona, M.; Diomede, L. Safety and toxicology of magnolol and honokiol. Planta Med. 2018, 84, 1151-1164. [CrossRef] [PubMed]

12. Brzonkalik, K.; Herrling, T.; Syldatk, C.; Neumann, A. The influence of different nitrogen and carbon sources on mycotoxin production in Alternaria alternata. Int. J. Food Microbiol. 2011, 147, 120-126. [CrossRef] [PubMed] 
13. Estiarte, N.; Crespo-Sempere, A.; Marín, S.; Sanchis, V.; Ramos, A.J. Exploring polyamine metabolism of Alternaria alternata to target new substances to control the fungal infection. Food Microbiol. 2017, 65, 193-204. [CrossRef] [PubMed]

14. Tudzynski, B. Nitrogen regulation of fungal secondary metabolism in fungi. Front. Microbiol. 2014, 5, 656. [CrossRef]

15. Pfannmüller, A.; Boysen, J.M.; Tudzynski, B. Nitrate assimilation in Fusarium fujikuroi is controlled by multiple levels of regulation. Front. Microbiol. 2017, 8, 381. [CrossRef]

16. Adnan, M.; Zheng, W.; Islam, W.; Arif, M.; Abubakar, Y.S.; Wang, Z.; Lu, G. Carbon catabolite repression in filamentous fungi. Int. J. Mol. Sci. 2018, 19, 48. [CrossRef]

17. Beattie, S.R.; Mark, K.M.K.; Thammahong, A.; Ries, L.N.A.; Dhingra, S.; Caffrey-Carr, A.K.; Cheng, C.; Black, C.C.; Bowyer, P.; Bromley, M.J.; et al. Filamentous fungal carbon catabolite repression supports metabolic plasticity and stress responses essential for disease progression. PLoS Pathog. 2017, 13, e1006340. [CrossRef]

18. Yang, M.; Lu, L.; Li, S.; Zhang, J.; Li, Z.; Wu, S.; Guo, Q.; Liu, H.; Wang, C. Transcriptomic insights into benzenamine effects on the development, aflatoxin biosynthesis, and virulence of Aspergillus flavus. Toxins (Basel) 2019, 11, 70. [CrossRef]

19. Zhao, X.; Zhi, Q.Q.; Li, J.Y.; Keller, N.P.; He, Z.M. The antioxidant gallic acid inhibits aflatoxin formation in Aspergillus flavus by modulating transcription factors farB and creA. Toxins (Basel) 2018, 10, 270. [CrossRef]

20. Fasoyin, O.E.; Wang, B.; Qiu, M.; Han, X.; Chung, K.R.; Wang, S. Carbon catabolite repression gene creA regulates morphology, aflatoxin biosynthesis and virulence in Aspergillus flavus. Fungal Genet. Biol. 2018, 115, 41-51. [CrossRef]

21. Da Cruz Cabral, L.; Rodríguez, A.; Delgado, J.; Patriarca, A. Understanding the effect of postharvest tomato temperatures on two toxigenic Alternaria spp. strains: Growth, mycotoxins and cell-wall integrity-related gene expression. J. Sci. Food Agric. 2019, 99, 6689-6695. [CrossRef] [PubMed]

22. Maggio-Hall, L.A.; Wilson, R.A.; Keller, N.P. Fundamental contribution of $\beta$-oxidation to polyketide mycotoxin production in planta. Mol. Plant-Microbe Interact. 2005, 18, 783-793. [CrossRef] [PubMed]

23. Poirier, Y.; Antonenkov, V.D.; Glumoff, T.; Hiltunen, J.K. Peroxisomal $\beta$-oxidation-A metabolic pathway with multiple functions. Biochim. Biophys. Acta Mol. Cell Res. 2006, 1763, 1413-1426. [CrossRef] [PubMed]

24. Montibus, M.; Pinson-Gadais, L.; Richard-Forget, F.; Barreau, C.; Ponts, N. Coupling of transcriptional response to oxidative stress and secondary metabolism regulation in filamentous fungi. Crit. Rev. Microbiol. 2015, 41, 295-308. [CrossRef] [PubMed]

25. Sieńko, M.; Natorff, R.; Skoneczny, M.; Kruszewska, J.; Paszewski, A.; Brzywczy, J. Regulatory mutations affecting sulfur metabolism induce environmental stress response in Aspergillus nidulans. Fungal Genet. Biol. 2014, 65, 37-47. [CrossRef]

26. Wang, L.; Jiang, N.; Wang, D.; Wang, M. Effects of essential oil citral on the growth, mycotoxin biosynthesis and transcriptomic profile of Alternaria alternata. Toxins (Basel) 2019, 11, 553. [CrossRef]

27. Wang, M.; Sun, X.; Yu, D.; Xu, J.; Chung, K.; Li, H. Genomic and transcriptomic analyses of the tangerine pathotype of Alternaria alternata in response to oxidative stress. Sci. Rep. 2016, 6, 1-11. [CrossRef]

28. Chen, L.H.; Lin, C.H.; Chung, K.R. A nonribosomal peptide synthetase mediates siderophore production and virulence in the citrus fungal pathogen Alternaria alternata. Mol. Plant Pathol. 2013, 14, 497-505. [CrossRef]

29. Pani, G.; Scherm, B.; Azara, E.; Balmas, V.; Jahanshiri, Z.; Carta, P.; Fabbri, D.; Dettori, M.A.; Fadda, A.; Dessì, A.; et al. Natural and natural-like phenolic inhibitors of type B trichothecene in vitro production by the wheat (Triticum sp.) pathogen Fusarium culmorum. J. Agric. Food Chem. 2014, 62, 4969-4978. [CrossRef] [PubMed]

30. Li, W.; Yuan, S.; Sun, J.; Li, Q.; Jiang, W.; Cao, J. Ethyl p-coumarate exerts antifungal activity in vitro and in vivo against fruit Alternaria alternata via membrane-targeted mechanism. Int. J. Food Microbiol. 2018, 278, 26-35. [CrossRef]

31. Wang, M.; Jiang, N.; Wang, Y.; Jiang, D.; Feng, X. Characterization of phenolic compounds from early and late ripening sweet cherries and their antioxidant and antifungal activities. J. Agric. Food Chem. 2017, 65, 5413-5420. [CrossRef] [PubMed]

32. Lee, C.W.; Hu, S.C.S.; Yen, F.L.; Hsu, L.F.; Lee, I.T.; Lin, Z.C.; Tsai, M.H.; Huang, C.L.; Liang, C.J.; Chiang, Y.C. Magnolol nanoparticles exhibit improved water solubility and suppress TNF- $\alpha$-induced VCAM-1 expression in endothelial cells. J. Biomed. Nanotechnol. 2017, 13, 255-268. [CrossRef] [PubMed] 
33. Xu, L.; Tao, N.; Yang, W.; Jing, G. Cinnamaldehyde damaged the cell membrane of Alternaria alternata and induced the degradation of mycotoxins in vivo. Ind. Crops Prod. 2018, 112, 427-433. [CrossRef]

34. Palumbo, J.D.; O'Keeffe, T.L.; Mahoney, N.E. Inhibition of ochratoxin A production and growth of Aspergillus species by phenolic antioxidant compounds. Mycopathologia 2007, 164, 241-248. [CrossRef] [PubMed]

35. Atanasova-Penichon, V.; Barreau, C.; Richard-Forget, F. Antioxidant secondary metabolites in cereals: Potential involvement in resistance to Fusarium and mycotoxin accumulation. Front. Microbiol. 2016, 7, 566. [CrossRef] [PubMed]

36. Saha, D.; Fetzner, R.; Burkhardt, B.; Podlech, J.; Metzler, M.; Dang, H.; Lawrence, C.; Fischer, R. Identification of a polyketide synthase required for alternariol (AOH) and alternariol-9-methyl ether (AME) formation in Alternaria alternata. PLoS ONE 2012, 7, e40564. [CrossRef]

37. Wang, P.; Ma, L.; Jin, J.; Zheng, M.; Pan, L.; Zhao, Y.; Sun, X.; Liu, Y.; Xing, F. The anti-aflatoxigenic mechanism of cinnamaldehyde in Aspergillus flavus. Sci. Rep. 2019, 9, 1-11. [CrossRef]

38. Jiang, T.; Zhang, X.F.; Wang, X.F.; Zhang, D.P. Arabidopsis 3-Ketoacyl-CoA Thiolase-2 (KAT2), an enzyme of fatty acid $\beta$-oxidation, is involved in ABA signal transduction. Plant Cell Physiol. 2011, 52, 528-538. [CrossRef]

39. Brakhage, A.A. Regulation of fungal secondary metabolism. Nat. Rev. Microbiol. 2013, 11, 21-32. [CrossRef]

40. Han, X.; Qiu, M.; Wang, B.; Yin, W.B.; Nie, X.; Qin, Q.; Ren, S.; Yang, K.; Zhang, F.; Zhung, Z.; et al. Functional analysis of the nitrogen metabolite repression regulator gene nmrA in Aspergillus flavus. Front. Microbiol. 2016, 7, 1794. [CrossRef]

41. Ries, L.N.A.; Beattie, S.R.; Espeso, E.A.; Cramer, R.A.; Goldman, G.H. Diverse regulation of the CreA carbon catabolite repressor in Aspergillus nidulans. Genetics 2016, 203, 335-352. [CrossRef] [PubMed]

42. Kotaka, M.; Johnson, C.; Lamb, H.K.; Hawkins, A.R.; Ren, J.; Stammers, D.K. Structural Analysis of the Recognition of the negative regulator NmrA and DNA by the zinc finger from the GATA-type transcription factor AreA. J. Mol. Biol. 2008, 381, 373-382. [CrossRef] [PubMed]

43. Giese, H.; Sondergaard, T.E.; Sørensen, J.L. The AreA transcription factor in Fusarium graminearum regulates the use of some nonpreferred nitrogen sources and secondary metabolite production. Fungal Biol. 2013, 117, 814-821. [CrossRef] [PubMed]

44. Macios, M.; Caddick, M.X.; Weglenski, P.; Scazzocchio, C.; Dzikowska, A. The GATA factors AREA and AREB together with the co-repressor NMRA, negatively regulate arginine catabolism in Aspergillus nidulans in response to nitrogen and carbon source. Fungal Genet. Biol. 2012, 49, 189-198. [CrossRef]

45. Reverberi, M.; Gazzetti, K.; Punelli, F.; Scarpari, M.; Zjalic, S.; Ricelli, A.; Fabbri, A.A.; Fanelli, C. Aoyap1 regulates OTA synthesis by controlling cell redox balance in Aspergillus ochraceus. Appl. Microbiol. Biotechnol. 2012, 95, 1293-1304. [CrossRef] [PubMed]

46. Ponts, N.; Pinson-Gadais, L.; Barreau, C.; Richard-Forget, F.; Ouellet, T. Exogenous $\mathrm{H}_{2} \mathrm{O}_{2}$ and catalase treatments interfere with Tri genes expression in liquid cultures of Fusarium graminearum. FEBS Lett. 2007, 581, 443-447. [CrossRef]

47. Reverberi, M.; Zjalic, S.; Ricelli, A.; Punelli, F.; Camera, E.; Fabbri, C.; Picardo, M.; Fanelli, C.; Fabbri, A.A. Modulation of antioxidant defense in Aspergillus parasiticus is involved in aflatoxin biosynthesis: A role for the ApyapA gene. Eukaryot. Cell 2008, 7, 988-1000. [CrossRef]

48. Caceres, I.; El Khoury, R.; Bailly, S.; Oswald, I.P.; Puel, O.; Bailly, J.D. Piperine inhibits aflatoxin B 1 production in Aspergillus flavus by modulating fungal oxidative stress response. Fungal Genet. Biol. 2017, 107, 77-85. [CrossRef]

49. Wang, Y.; Feng, K.; Yang, H.; Zhang, Z.; Yuan, Y.; Yue, T. Effect of cinnamaldehyde and citral combination on transcriptional profile, growth, oxidative damage and patulin biosynthesis of Penicillium expansum. Front. Microbiol. 2018, 9, 597. [CrossRef]

50. Sun, Q.; Shang, B.; Wang, L.; Lu, Z.; Liu, Y. Cinnamaldehyde inhibits fungal growth and aflatoxin $\mathrm{B}_{1}$ biosynthesis by modulating the oxidative stress response of Aspergillus flavus. Appl. Microbiol. Biotechnol. 2016, 100, 1355-1364. [CrossRef]

51. Rodríguez-Peña, J.M.; García, R.; Nombela, C.; Arroyo, J. The high-osmolarity glycerol (HOG) and cell wall integrity (CWI) signalling pathways interplay: A yeast dialogue between MAPK routes. Yeast 2010, 27, 495-502. [CrossRef] [PubMed] 
52. Graf, E.; Schmidt-Heydt, M.; Geisen, R. HOG MAP kinase regulation of alternariol biosynthesis in Alternaria alternata is important for substrate colonization. Int. J. Food Microbiol. 2012, 157, 353-359. [CrossRef] [PubMed]

53. Kohut, G.; Ádám, A.L.; Fazekas, B.; Hornok, L. N-starvation stress induced FUM gene expression and fumonisin production is mediated via the HOG-type MAPK pathway in Fusarium proliferatum. Int. J. Food Microbiol. 2009, 130, 65-69. [CrossRef] [PubMed]

54. Stoll, D.; Schmidt-Heydt, M.; Geisen, R. Differences in the regulation of ochratoxin A by the HOG pathway in Penicillium and Aspergillus in response to high osmolar environments. Toxins (Basel) 2013, 5, 1282-1298. [CrossRef] [PubMed]

55. Da Cruz Cabral, L.; Delgado, J.; Patriarca, A.; Rodríguez, A. Differential response to synthetic and natural antifungals by Alternaria tenuissima in wheat simulating media: Growth, mycotoxin production and expression of a gene related to cell wall integrity. Int. J. Food Microbiol. 2019, 292, 48-55. [CrossRef] [PubMed]

56. Hayes, B.M.E.; Anderson, M.A.; Traven, A.; Van Der Weerden, N.L.; Bleackley, M.R. Activation of stress signalling pathways enhances tolerance of fungi to chemical fungicides and antifungal proteins. Cell. Mol. Life Sci. 2014, 71, 2651-2666. [CrossRef] [PubMed]

57. Jiang, N.; Li, Z.; Wang, L.; Li, H.; Zhu, X.; Feng, X.; Wang, M. Effects of ultraviolet-c treatment on growth and mycotoxin production by Alternaria strains isolated from tomato fruits. Int. J. Food Microbiol. 2019, 311. [CrossRef]

58. Meena, M.; Swapnil, P.; Upadhyay, R.S. Isolation, characterization and toxicological potential of Alternaria-mycotoxins (TeA, AOH and AME) in different Alternaria species from various regions of India. Sci. Rep. 2017, 7, 1-19. [CrossRef]

Publisher's Note: MDPI stays neutral with regard to jurisdictional claims in published maps and institutional affiliations. 